\title{
O UNIVERSO DA BIBLIOTECONOMIA NOS DIVERSOS AMBIENTES INFORMACIONAIS COM O USO DAS TECNOLOGIAS ABERTAS
}

THE UNIVERSE OF LIBRARY IN THE VARIOUS ENVIRONMENTS INFORMATIONAL WITH THE USE OF TECHNOLOGIES OPEN

Caros leitores,

Temos o prazer de anunciar mais uma edição da RDBCI. Esta edição traz como temática “ $\boldsymbol{O}$ universo da biblioteconomia nos diversos ambientes informacionais com o uso das tecnologías abertas", além da novidade de contribuição de (05) cinco textos em inlgês. São excelentes trabalhos que nos brindam com a tradução para outro idioma, cumprindo dessa forma uma das metas que nos propusemos a realizar nas políticas editoriais desde o final de 2015. Esta meta visa melhor qualificar e dar expansibilidade aos textos em outros idiomas, propiciando a integração além da fronteira e barreiras lingüísticas.

Ao trabalharmos na reunião dos textos para a elaboração dessa temática em questão, realizamos uma reflexão em função dos textos submetidos e analizamos cada um deles e sua contextualização nas várias frentes dos serviços e atividades relacionados extremamente com a área da Biblioteconomia, e encontramos relações com outras áreas como a Educação e a Tecnologia.

Falando da Biblioteconomia como uma disciplina que converge claramente para a organização de técnicas voltadas para as bibliotecas, cada vez mais nos atenuamos na visualização da sua expansão e multidisciplinaridade em crescimento com outras áreas. Tem um lado prático e envolvente tanto para veteranos como para iniciantes, e percebe-se que a Biblioteconomia não ficou estagnada no tempo, mas simplesmente avança cada vez mais com a integração das plataformas e inovações tecnológicas que ajudam em muito nas rotinas dos bibliotecários, dos professores e dos pesquisadores que manifestam interesse no envolvimento de suas pesquisas com a área da informação.

Nesse caminho, entra em ação o campo da Ciência da Informação, que concebe um lado mais teórico de sua atuação que, complementando a Biblioteconomia, esse campo do saber

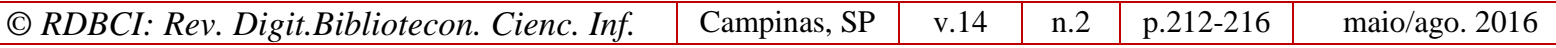


promove grande parte de seus estudos à realização de pesquisas e descobertas na área da informação, e torna possível a prática da multidisciplinaridade em prol dos objetivos da evolução do profissional bibliotecário.

Sendo assim, ao retratarmos essas rotinas e atividades visualizadas nos textos submetidos, percebemos a grande importância e avanços que tanto a Biblioteonomia quanto a Ciência da Informação praticaram nesses longos anos de convivencia de academia, resgatando a possibilidade de trabalho coletivo e benéfico para toda a sociedade da informação e do conhecimento, com o destaque das tecnologias abertas.

As tecnologias abertas, fomentadas precisamente nos ambientes informacionais, têm se revelado instrumentos alavancadores de inovação e propriciação de processos de trabalhos colaborativos. Com isso, vale a pena enveredar-se na leitura dos trabalhos que garantiram a confecção de uma temática atual, contemporânea e de constante ebulição com os estudos e pesquisas realizados nessas áreas do conhecimento.

Nesta edição, contamos com sete (07) artigos, um (01) relato de experiencia e uma (01) comunicação, sendo que, como comentado anteriormente, um dos artigos está escrito originalmente em inglês e quatro deles foram traduzidos para esse mesmo idioma.

Na seção ARTIGOS, Gabrielle Francinne Tanus, da Universidade Federal de Minas Gerais, contribui com o texto intitulado: "A constituição da biblioteconomia científica: um olhar histórico", que tem como propósito relatar um momento em que as mudanças suscitaram uma virada na postura do campo da Biblioteconomia científica, comparando-a com definições marcadas nas eras pré-científica e proto-científica, as quais demonstram um movimento em direção a constituição desse saber, refletidas em práticas e em algumas produções, sobretudo, os manuais, voltados também para a instituição biblioteca.

No segundo artigo intitulado "A redefinição da biblioteca no século XXI: de ambientes informacionais a espaços de convivencia”, de autoria de Jorge Santa Anna, da Universidade Federal do Espírito Santo, demonstra-se o novo cenário que se idealiza para a biblioteca do futuro, na percepção da literatura e de bibliotecários. Para tanto, o estudo apresenta a evolução da biblioteca ao longo dos anos, expondo os serviços e produtos oferecidos com 
base nas novas tecnologías e discorrendo acerca das atividades culturais e de entretenimento realizadas nos espaços informacionais, além de refletir a opinião de bibliotecários quanto às atividades culturais e sociais realizadas nas bibliotecas.

Em “As competências, os perfis e os aspectos sociais do bibliotecário na educação”, escrito por Claudio Marcondes de Castro Filho, da Universidade de São Paulo, o autor considera que a biblioteca escolar deva ser reconhecida com um equipamento cultural, uma instituição social, com o intuito de integrar a sociedade da informação, estabelecendo novos conceitos e se adequando às realidades sociais, culturais, educativas e tecnológicas da sociedade. Diante disso, o autor tem como objetivo neste estudo, tendo como escopo a biblioteca escolar, apontar os perfis, as competências e os aspectos sociais do bibliotecário no espaço contemporâneo.

No quarto artigo, Ana Cláudia Carvalho de Miranda, do Tribunal de Justiça do Rio Grande do Norte, Mônica Marques Carvalho Gallotti, da Universidade Federal do Rio Grande do Norte, e Erlano Silva de Miranda, da Receita Federal do Rio Grande do Norte, apresentam o texto sobre "A gestão da qualidade como estratégia de suporte para o desenvolvimento de coleçoes em bibliotecas jurídicas", que se propõe a debater a questão da gestão da qualidade por meio do estudo do processo de Desenvolvimento de Coleções de Bibliotecas Jurídicas, fomentado por uma revisão de literatura nas áreas da Qualidade e do Desenvolvimento de Coleções, buscando identificar suas principais características enquadradas no universo específico das Bibliotecas Jurídicas.

Robson Dias Martins, da Universidade do Estado do Rio de Janeiro, com "Obstáculos para expansão do uso dos e-books na sociedade brasileira" aborda as dificuldades para expansão do uso dos e-books na sociedade brasileira, pretendendo por meio de uma revisão de literatura proporcionar formas para democratização do acesso, bem como o arrolamento de processos simplificados acerca da administração de coleções.

No sexto artigo, "Uma investigação sobre a autoria de dados científicos: teias de uma rede em construção", Jackson da Silva Medeiros, da Universidade Federal do Rio Grande do Sul, objetiva analisar a autoria científica a partir do compartilhamento de dados de pesquisa, utilizando a Teoria Ator-Rede (ANT) que busca, a partir de uma ideia de simetria entre 
humanos e não humanos, não assumir uma divisão entre essas entidades, possibilitando visualizar o estabelecimento e a dissolução de uma rede a partir das relações que se criam em diversos níveis. A investigação ocorreu junto ao Repositório de Dados de Estudos Ecológicos do Programa de Pesquisa em Biodiversidade (PPBio).

No sétimo e último artigo, trazemos uma contribuição originária do Reino Unido. Aquiles Alencar-Brayner, curador digital de coleções Latino-americanas da British Library, nos brinda com o texto sobre o programa de arquivo de páginas Web no Reino Unido, intitulado: "UK Web archive programme: a brief history of opportunities and challenges", em que o autor levanta algumas questões centrais em relação aos obstáculos tecnológicos e modelos curatoriais adotados para a preservação e acesso ao conteúdo publicado na Web, baseado no exemplo de desenvolvimento do programa de arquivos de páginas Web no Reino Unido, UK Web Archive.

Na seção RELATO DE EXPERIÊNCIA, Nalin Ferreira da Silveira e Willian Valmorbida, ambos do Centro Universitário Univates, apresentam o texto intitulado "Processo de etiquetagem para implantação da tecnologia RFID na biblioteca do centro universitário UNIVATES", que descreve o processo inicial de implantação da tecnologia de identificação por radiofrequência (RFID) no acervo da Biblioteca do Centro Universitário Univates, evidenciando os recursos humanos e de informática envolvidos no período de novembro de 2013 a março de 2014.

Na última seção COMUNICAÇÃO, Ilsa do Carmo Vieira Goulart, da Universidade Federal de Lavras, em seu texto intitulado "A configuração do espaço dos livros no interior da sala de aula", apresenta o modo como os livros estão dispostos em diferentes espaços físicos, no interior da sala de aula, e como são percebidos pelos docentes e discentes, regulamentando ações e atuações dos sujeitos. 
Sintam-se a vontade para degustarem a leitura dos excenlentes textos publicados nessa edição!

Gildenir Carolino Santos ${ }^{1}$ Danielle Thiago Ferreira ${ }^{2}$

Editores Científicos

Maio/2016
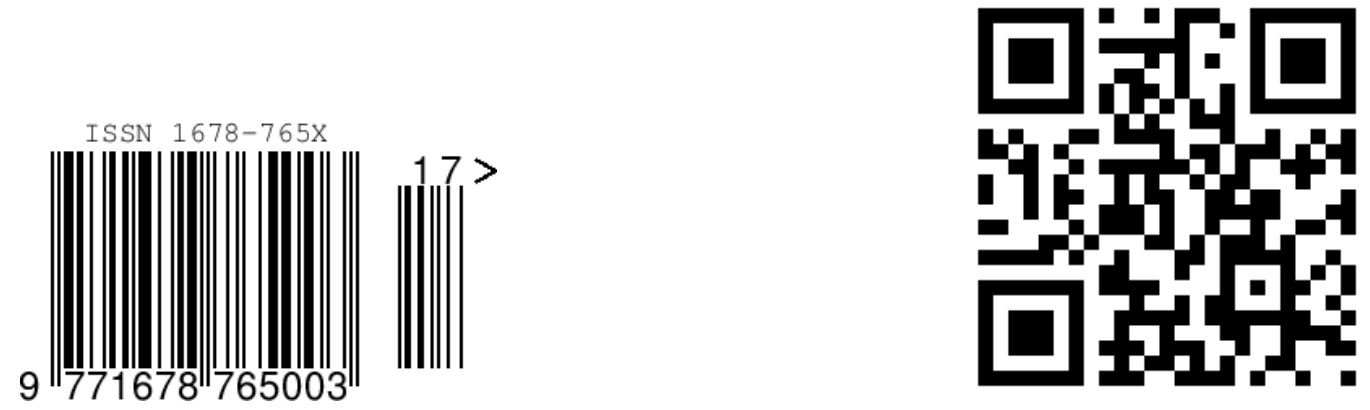

\footnotetext{
${ }^{1}$ Bibliotecário. Doutor em Educação (UNICAMP). Sistema de Bibliotecas - Portal de Periódicos Eletrônicos Científicos - UNICAMP. Campinas, SP - Brasil. ORCID: http://orcid.org/0000-0002-4375-6815. E-mail: gilbfe@unicamp.br

${ }^{2}$ Bibliotecária. Doutora dem Ciência da Informação (USP). Biblioteca da Área de Engenharias - UNICAMP. Campinas, SP - Brasil. ORCID: http://orcid.org/0000-0002-0957-4022. E-mail: danif@ unicamp.br

\begin{tabular}{l|l|l|l|l|l} 
(C) RDBCI: Rev. Digit.Bibliotecon. Cienc. Inf. & Campinas, SP & v.14 & n.2 & p.212-216 & maio/ago. 2016 \\
\hline
\end{tabular}
} 